University of Nebraska - Lincoln

DigitalCommons@University of Nebraska - Lincoln

The Nebraska Educator: A Student-Led Journal Department of Teaching, Learning and Teacher

Education

$10-2020$

\title{
EmPOWER: An Adaptable Writing Intervention
}

Carly Dinnes

Bowling Green State University, cdinnes@bgsu.edu

Follow this and additional works at: https://digitalcommons.unl.edu/nebeducator

Part of the Language and Literacy Education Commons, Other Teacher Education and Professional Development Commons, Special Education and Teaching Commons, and the Speech Pathology and Audiology Commons

Dinnes, Carly, "EmPOWER: An Adaptable Writing Intervention" (2020). The Nebraska Educator: A StudentLed Journal. 46.

https://digitalcommons.unl.edu/nebeducator/46

This Article is brought to you for free and open access by the Department of Teaching, Learning and Teacher Education at DigitalCommons@University of Nebraska - Lincoln. It has been accepted for inclusion in The Nebraska Educator: A Student-Led Journal by an authorized administrator of DigitalCommons@University of Nebraska - Lincoln. 


\title{
EmPOWER: An Adaptable Writing Intervention
}

\author{
Carly Dinnes \\ Department of Teaching, Learning, and Teacher Education \\ University of Nebraska-Lincoln
}

\begin{abstract}
EmPOWER is a six-stage writing intervention designed by speech-language pathologists to improve the expository writings of school-aged children with language learning and executive function disabilities. The intervention uses scaffolded instruction to transform struggling students into independent and self-regulating writers by training the students to use a variety of supports (e.g., graphic organizers, checklists) and strategies (e.g., referring back to the writing prompt) throughout the writing process. Many key features of the EmPOWER approach to writing instruction directly support components described in cognitive models of writing, which indicates that EmPOWER is a theory-guided writing intervention that may benefit a wide range of individuals beyond just school-aged children. Thus, this analysis provides an overview of the EmPOWER approach, compares the intervention's key features to the most recent conceptualization of the cognitive mechanisms involved in the writing process, and provides a discussion for adapting EmPOWER to a specific population (i.e., people with aphasia).
\end{abstract}

Keywords: writing, intervention, instruction, theory, aphasia

doi: 10.32873/unl.dc.ne001 
Writing is a complex form of communication that requires the recruitment and coordination of multiple skills to effectively convey a meaningful and concise message. Multiple cognitive skills (e.g., recalling relevant information, organizing the information into a meaningful sequence, and evaluating the quality of the message generated) must be employed in tandem with multiple linguistic skills (e.g., retrieving specific words from an internal lexicon to form a message, applying syntactic knowledge to guide message composition, and reading the message in order to identify errors and ambiguities) throughout the writing process to ensure effective communication between writer and reader. The inherent complexity of this method of communication makes writing a difficult skill to master and susceptible to the effects of cognitive and linguistic impairments resulting from developmental or acquired disorders.

Researchers in the fields of education, special education, and speech-language pathology have explored various ways of providing effective writing instruction and intervention for students with and without impairments. Several researchers specifically in the fields of special education and education have developed writing models that detail just how the writing process works with the goal of informing instructional and intervention practices (for examples of writing models, see Graham, 2018; Hayes \& Flower, 1980; Kellogg, 1996; Scardamalia \& Bereiter, 1987; and Zimmerman \& Risemberg, 1997). In addition to theoretical models of the writing process, the writing literature contains multiple experimental research studies that have led to the development of a variety of recommendations for scaffolding writing development such as providing students with models of writing to review, more opportunities to write, and the option to write either by hand or using a computer (Graham \& Perin, 2007a, 2007b; Graham, Harris, \& Chambers, 2016; Graham, Harris, \& Santangelo, 2015; Mason \& Graham, 2008; National Commission on Writing, 2003; National Commission on Writing, 2006; Rogers \& 
Graham, 2008). Also included in the literature is a wide variety of specific educational and intervention strategies that detail more structured approaches to developing and supporting students' written expression (e.g., Self-Regulated Strategy Development, EmPOWER; Harris, Graham, \& Mason, 2003; Bashir \& Singer, 2006; Singer \& Bashir, 2004).

Significantly less literature is available on adult writing. This is a problem for professionals working with adults who have acquired writing difficulties as a result of injuries such as cerebrovascular accident (CVA; i.e., stroke) or traumatic brain injury (TBI). Recent studies identified writing challenges after TBI as having a negative impact on engagement in writing for academic (e.g., report writing, note taking), vocational (e.g., work documentation), social (e.g., email, text messaging), and personal (e.g., journaling, reminder notes) purposes (Dinnes \& Hux, 2018; Dinnes, Hux, Holmen, Martens, \& Smith, 2018; Ledbetter, Sohlberg, Fickas, Horney, \& McIntosh, 2017). This pervasive interference is more pronounced for people with aphasia.

Aphasia is a language disorder frequently caused by CVA and is the source of persistent difficulty with expressive language—such as speaking or writing—as well as comprehending written and spoken information. Much of the current literature on adult writing interventions focuses on people with aphasia; however, these studies investigate the effectiveness of interventions to improve the generation of single words or simple sentences for people struggling with severe writing impairments. Thus, scant research is currently available to provide intervention recommendations for people with less severe acquired writing difficulties.

The scarcity of writing intervention literature for adults struggling with effective written communication necessitates the reference and adaptation of writing instruction and intervention recommendations developed for use with school-age children. Ideally, writing models should 
guide both the development and adaptation of writing interventions in order to maximize the efficacy and potency of the intervention by ensuring that multiple, if not all, aspects of the process are directly targeted by the intervention; however, not all researchers and clinicians consider referencing models when developing interventions. Thus, the purpose of this analysis is to (a) examine EmPOWER, a structured approach to writing intervention, (b) compare EmPOWER to a new writing model to identify areas of the writing process that are and are not directly targeted by EmPOWER, and (c) provide a discussion on how EmPOWER can be adapted through modifications and supplementations to become an effective writing intervention for people with aphasia.

\section{EmPOWER}

EmPOWER is an intervention that treats writing as a problem-solving task and, thus, specifically targets the various language and executive function skills that underlie the writing process (Bashir \& Singer, 2006; Singer \& Bashir, 2004). This strategy is an adaptation and expansion of the POWER strategy (Englert et al., 1988), which prompted students with learning disabilities to Plan, Organize, Write, Edit, and Revise. EmPOWER, however, was specifically designed to support students with language and executive function difficulties (Bashir \& Singer, 2006; Singer \& Bashir, 2004). As such, EmPOWER is a self-regulation approach that teaches writers to employ strategies to assist in the identification and achievement of writing goals using six steps: Evaluate, make a Plan, Organize, Work, Evaluate, and Re-work (Bashir \& Singer, 2006; Singer \& Bashir, 2004). This approach is implemented as a form of scaffolded instruction in which less support is provided as students begin mastering the various components of the strategy (Bashir \& Singer, 2006; Singer \& Bashir, 2004). Given sufficient time and practice, students will be able to independently use the EmPOWER approach to support their writing 
(Bashir \& Singer, 2006; Singer \& Bashir, 2004). Although EmPOWER was originally designed by speech-language pathologists (SLPs) to address the expository writing needs of school-aged children with executive function disorders and language learning disabilities, the approach can be adapted for use across a variety of conditions and with a variety of individuals (Bashir \& Singer, 2006; Singer \& Bashir, 2004). Furthermore, teachers can easily adopt and adapt EmPOWER to suit their needs in the classroom.

The Evaluate stage of EmPOWER cues students to verify their understanding of the writing prompt by identifying specific instructions and segmenting the prompt into separate components (Bashir \& Singer, 2006; Singer \& Bashir, 2004). Students are taught to identify the action words embedded in the prompt (e.g., describe, tell, explain) and then use this information to determine the number of components their written response must have. For example, students given the prompt, "Select an important figure from this unit, describe their achievements, and explain why their work was important," would identify three action words (i.e., "select", "describe", and "explain") and three corresponding components for their writing: (a) identify an individual discussed recently, (b) summarize the individual's work, and (c) highlight the impact of that work.

The second stage, make a Plan, teaches students to outline their response to the writing prompt (Bashir \& Singer, 2006; Singer \& Bashir, 2004). Students determine their goals for the writing, select a topic, and generate a checklist of tasks to accomplish based on the action words and number of parts the prompt requires. Students also select an appropriate graphic organizer to scaffold their idea generation and the organization process (e.g., webs, Venn diagrams, timelines); for example, a student writing about Napoleon Bonaparte may select a timeline to chart his accomplishments in relation to other relevant historical events. As a caveat, pre-made 
organizers provide a set structure that may not meet the individual needs of every student. Thus, it may be beneficial to train students to generate their own graphic organizers to ensure their ideas will not be limited by the design of pre-made organizers. At the end of the make a Plan stage, students reflect on whether they have generated enough ideas to begin mapping them using the graphic organizer or if they are missing any relevant information.

In the Organize stage of EmPOWER, students map their ideas using the selected graphic organizer and determine an appropriate sequence for presenting the information in their writing (e.g., chronological reporting of events, prioritization of topic importance; Bashir \& Singer, 2006; Singer \& Bashir, 2004). Students refer back to the writing prompt and their work in the previous stages to ensure they are generating relevant and sufficient ideas to achieve their writing goals. Thus, students are prompted to assess their idea generation, content organization, and whether more or less information is required. In the case of the example student writing about Napoleon Bonaparte, the student may have generated ideas and information about Bonaparte's exile during the make a Plan stage. However, when cued to refer back to the writing prompt in the Organize stage, the student may now deem the information irrelevant and discard it.

In the Work stage, students follow a basic template to transform the ideas generated in the previous stages into a connected writing (Bashir \& Singer, 2006; Singer \& Bashir, 2004). First, students begin composing the introductory paragraph by generating a topic sentence and identifying the associated subtopics. This paragraph clearly states the focus of the writing and previews important information presented later. In the following paragraphs, students provide details and supporting information (e.g., examples, facts) for each subtopic. The initial composition of these paragraphs may be brief (e.g., one or two sentences); however, students continue to finetune the writing by expanding on the information. Finally, the students compose 
the conclusion to the writing using the PSST strategy (i.e., paraphrase the topic sentence, summarize the subtopics, and leave the reader thinking or feeling).

Students then return to the Evaluate stage of EmPOWER to assess the writing they have generated using the COLA checklist (i.e., Content, Organization, Language, and Appearance; Bashir \& Singer, 2006; Singer \& Bashir, 2004). This checklist prompts students to determine whether their writing is relevant to the prompt, well-organized, repetitive, or contains errors (e.g., spelling, grammar). In this stage, students are also encouraged to get feedback on their writing from others (e.g., teacher, peers, parents). Students then use this feedback and the COLA checklist to Re-work their writing in the last stage of EmPOWER.

\section{Assessing EmPOWER Using a Cognitive Model of Writing}

EmPOWER was designed primarily to support the language and executive functioning mechanisms that drive the writing process in school-age children with language learning disabilities and/or executive function disorders (Bashir \& Singer, 2006; Singer \& Bashir, 2004). As a result, this intervention supports many of the elements included in the various cognitive models of the writing process (e.g., Graham, 2018; Hayes \& Flower, 1980; Scardamalia \& Bereiter, 1987). In particular, Graham's (2018) model, which represents the most recent conceptualization of the cognitive components driving the writing process, identifies multiple mechanisms that EmPOWER was designed to support. Table 1 provides an overview of the alignment between EmPOWER and the components of Graham's (2018) model.

Graham's (2018) model identifies four primary facets (i.e., long-term memory resources, control mechanisms, production processes, and modulators) of the writing process as well as multiple supporting factors for each facet. The long-term memory facet and its subcomponents (i.e., knowledge and beliefs) address the writer's beliefs and knowledge of writing, his/her role 
as a writer, text in general, language, and other concepts as they relate to the writer's particular circumstances as well as the type and topic of writing. The control mechanisms facet and its subcomponents (i.e., working memory, attention, and several executive control factors) focus on the implementation and coordination of multiple executive functions to successfully generate a written message. The model's production processes and its subcomponents (i.e., conceptualization, ideation, translation, transcription, and reconceptualization) address the generation of ideas and the transformation of those ideas into written language. The final facet, modulators, includes factors that may impact the writing process, such as the writer's emotional state, personality, and physiological status.

Several elements of EmPOWER's structure align with Graham's (2018) cognitive model of the writing process. All of Graham's (2018) control mechanisms are addressed by EmPOWER through the use of organizers, checklists, and goal setting strategies. These strategies support students' attention to the writing task, comprehension of the instructions for completing the task, and working memory to track both the instructions and the ideas generated in response to the prompt (Bashir \& Singer, 2006; Singer \& Bashir, 2004). EmPOWER's make a Plan stage directly supports Graham's (2018) planning factor for writing through direct cuing and additional supports such as templates and graphic organizers (Bashir \& Singer, 2006; Singer \& Bashir, 2004). Similar to the monitoring and react components of Graham's (2018) model, students using the EmPOWER approach monitor their writing to some degree throughout their engagement in all six stages, but especially during the second Evaluate stage (e.g., referring back to their writing goals, revising their written work; Bashir \& Singer, 2006; Singer \& Bashir, 2004). 
EmPOWER addresses Graham's (2018) production processes in a similar manner. The conceptualization component (Graham, 2018) for comprehending the writing task is captured by EmPOWER's first Evaluate stage, which tasks students with analyzing the writing prompt (Bashir \& Singer, 2006; Singer \& Bashir, 2004). EmPOWER's make a Plan phase aligns with Graham's (2018) ideation component by directing students to plot their approach to writing through a series of pre-writing tasks (e.g., selecting a graphic organizer for generating ideas, completing a template; Bashir \& Singer, 2006; Singer \& Bashir, 2004). Translation and transcription (Graham, 2018) are addressed through a combination of EmPOWER's make a Plan, Organize, and Work phases (Bashir \& Singer, 2006; Singer \& Bashir, 2004). Students' ideas are generated and initially transformed into written language as brief notes or sentences in an organizer and then expanded upon as part of a template. Students further transform their ideas into more formal and connected writings (Graham, 2018) during the Work stage. The writing is then analyzed and, if necessary, reconceptualized during the last stages of EmPOWER (i.e., the second Evaluate stage and Re-work phase; Bashir \& Singer, 2006; Singer \& Bashir, 2004).

The long-term memory resources discussed by Graham (2018) are also addressed in part by EmPOWER. The first Evaluate stage specifically teaches students strategies for analyzing the writing prompt and the later stages train students to evaluate their own writing by reading what they have generated and determining if adjustments are needed (Bashir \& Singer, 2006; Singer \& Bashir, 2004). Thus, these aspects of EmPOWER address several factors of the reading components of knowledge described by Graham (2018). Likewise, EmPOWER supports several elements of writing knowledge (Graham, 2018) by training students to proceed through a series of steps (e.g., plan, organize, use templates and graphic organizers) that support the generation of 
incrementally longer sentences for their final written product (Bashir \& Singer, 2006; Singer \& Bashir, 2004).

There are aspects of Graham's (2018) cognitive model for writing that are only partially supported or are not supported at all by EmPOWER (Bashir \& Singer, 2006; Singer \& Bashir, 2004). Specifically reading and writing knowledge (Graham, 2018) are partially supported by EmPOWER; knowledge about reading sources for relevant information, transcription skills (e.g., spelling, keyboarding, handwriting), and the intended audience for the writing are not addressed. EmPOWER also does not address other aspects of knowledge (e.g., oral language knowledge, multiple language knowledge, and listening language knowledge), the belief component of the long-term memory facet, or the potential modulators for writing (Graham, 2018).

Overall, the EmPOWER intervention addresses many of the components identified in Graham's (2018) cognitive model; however, key components are not addressed or are only partially accounted for (Bashir \& Singer, 2006; Singer \& Bashir, 2004). The model's control mechanisms and production processes are fully supported by a variety of EmPOWER's stages and strategies but the knowledge subcomponent of Graham's (2018) long-term memory resources is only partially addressed. Thus, EmPOWER provides a great deal of support for the executive functioning mechanisms that underlie the writing process but only partial support for writing's language components (Bashir \& Singer, 2006; Singer \& Bashir, 2004). EmPOWER does not address any of the modulators or the belief subcomponent of the long-term memory resources described by Graham (2018), which further supports the conclusion that EmPOWER is an executive functioning-based intervention that also supports some language components. However, many of these components can be embedded during direct instruction to meet the 
needs of individual students and EmPOWER can be further adapted for use with writers of all ages and abilities.

\section{Adapting EmPOWER for People with Aphasia}

EmPOWER was originally designed to support the expository writing endeavors of school-age children with language learning and/or executive functioning disabilities (Bashir \& Singer, 2006; Singer \& Bashir, 2004). However, this approach can be modified to support several genres of writing (e.g., narrative, persuasive) as well as individuals older than school-age children who may have similar language and executive functioning difficulties. For instance, people with aphasia who experience language-based writing difficulties may benefit from an adaptation of the EmPOWER approach.

Several modifications are required for the EmPOWER approach to better address the needs of people with aphasia. Because aphasia is a language-specific disorder, executive functioning remains relatively intact.. Hence, implementing the EmPOWER approach with this population necessitates a greater emphasis on including supports for language. Adapting the reading level of text provided to people with aphasia to include simple sentences that are less taxing to decode and comprehend is one such support. Likewise, including meaningful pictures in addition to text can further support comprehension of the writing task. Training people with aphasia to implement strategies to support word finding difficulties (e.g., semantic feature analysis, circumlocution) provide people with aphasia with a means of self-talk to support language-related difficulties that may impact written expression. These language supports are adaptations that will increase the potency of implementing EmPOWER with people with aphasia. 
Incorporating training in the use of technology to write would also strengthen EmPOWER and is a well-documented recommendation for writing instruction (e.g., Graham et al., 2016; Graham et al., 2012; Graham, Harris, \& Chambers, 2016). Using a word processing program can support the production process of writing by clearly displaying the text, thus eliminating concerns about the legibility of the handwriting while simultaneously making the written message easier to edit. Additionally, most word processors provide features such as spelling and grammar checkers, a thesaurus, and text-to-speech capabilities that further support the writing process. Spelling and grammar checkers highlight writing units to indicate errors such as misspellings, incorrect word or punctuation choice, and repetitions of the previous word that people with aphasia may not attend to when writing by hand. Access to the word processor's thesaurus and an online dictionary can combat word choice and word retrieval difficulties by allowing people with aphasia to (a) verify word meanings and (b) look up words similar to the word they are unable to retrieve and peruse synonyms for the intended word. The text-to-speech feature would allow people with aphasia to listen to their written message aloud and potentially recognize errors in the message that they would be unable to recognize when reading their messages. Such use of the text-to-speech feature would also allow people with aphasia to identify errors that the spelling and grammar checker failed to identify.

The technological supports described above are readily available as part of most word processing programs or access to the Internet. Less readily available programs, such as word prediction software and speech-to-text features, can also support the language difficulties of people with aphasia. Word prediction programs provide a list of suggested words to continue the writing process after it is initiated, which may reduce the cognitive load associated with idea generation and word retrieval during online message composition. Speech-to-text programs 
allow an individual to dictate their intended message, which may reduce the cognitive load associated with dividing attention between composing and transcribing the message.

A final adaptation of EmPOWER for use with people with aphasia is to focus on functional writing tasks. EmPOWER was designed to support the expository writing of schoolage children in response to a specific writing prompt. As people with aphasia tend to be adults, this form of writing is not the most functional or appropriate focus for a writing intervention aimed at this population. Instead, EmPOWER can be adapted for use with composing emails, text messages, letters, or work documentation as appropriate to each individual. These types of writings do not typically have explicitly stated goals or directions for the writing, which would necessitate the adjustment of EmPOWER's first stage (i.e., evaluate the writing prompt) to include strategies for determining the implied purpose of the writing (e.g., answering questions posed in an email or text from an acquaintance, filling out work reports on a specific topic). However, the bulk of the EmPOWER approach would not require adjustment beyond streamlining the process as individuals increase in their level of mastery for the six stages to transform the original lengthy EmPOWER approach into a more efficient process.

For example, a person with aphasia who doesn't struggle with planning and organizing his/her writing may not need to include these stages in his/her writing process. Thus, instead of following the EmPOWER approach step-by-step, this individual would be able to shorten the process to include the initial evaluate stage, work stage, second evaluate stage, and the re-work stage. This simplified version of EmPOWER would provide the person with aphasia with the support and strategies necessary to compensate for language impairments affecting comprehension and expression skills but would not require the person to engage in the Planning and Organizing stages. 


\section{Conclusion}

EmPOWER is a self-regulation intervention aimed at improving the expository writing of school-age children with language learning and executive functioning disabilities (Bashir \& Singer, 2006; Singer \& Bashir, 2004). This intervention focuses heavily on supporting the executive functioning mechanisms driving the writing process through scaffolded instruction in the application of six writing stages (i.e., Evaluate, make a Plan, Organize, Work, Evaluate, and Re-work) and multiple supporting strategies (e.g., using a graphic organizer, expanding on a template). EmPOWER aligns with many of the cognitive writing mechanisms (i.e., control mechanisms, production processes, and certain knowledge-based long-term memory resources) identified by the most recent conceptualization of the writing process (Graham, 2018), which makes EmPOWER an appealing and theory-guided writing intervention. This analysis specifically focused on how EmPOWER can be adapted for use with people with aphasia; however, EmPOWER can be similarly modified by SLPs and teachers for use with a wide range of ages and abilities.

There is a degree of misalignment between EmPOWER and Graham's model (2018), however, that requires exploration. First, Graham's (2018) model represents the writing process in its cognitive entirety. It contains all of the cognitive components that direct and influence a writer, but these components exert differing levels of influence on writers based on factors such as age, experience, and other individual differences. Second, as EmPOWER was initially designed for use with developing writers, aspects of the misalignment to Graham's (2018) model may be attributed to differing perspectives between a model for writers in general compared to an intervention targeting school-age children. 
Third, differing perspectives between fields of study may also contribute to the misalignment between EmPOWER and Graham's (2018) model in that the field of speechlanguage pathology views language as a more complex and nuanced skill involved in written expression than researchers in the education and special education fields. Graham's (2018) model, along with many of the other writing models developed by education and special education researchers, focuses primarily on cognitive skills and devotes less attention to linguistic skills. Writing models developed by SLPs that explore the more detailed role language plays in written expression do exist (e.g., Bashir \& Singer, 2006), however, these models are less well-known than the models developed by researchers in the education and special education fields. Thus, future research on writing may benefit from the collaboration of researchers in the fields of education, special education, and speech-language pathology to develop a writing model that includes both cognitive and linguistic skills to better guide writing instruction and intervention. 


\section{Acknowledgements}

The author wishes to acknowledge the supportive feedback from Dr. Karen Hux and Dr. Michael Hebert in the composition of this manuscript. 


\section{References}

Bashir, A. S. \& Singer, B. D. (2006). Assisting students in becoming self-regulated writers. In T. Ukrainetz (Ed.), Contextualized language intervention: Scaffolding PreK - 12 literacy achievement (pp. 565-598). Greenville, SC: Thinking Publications.

Dinnes, C. \& Hux, K. (2018). A multicomponent writing intervention for a college student with mild brain injury. Communication Disorders Quarterly, 39(4), 490500. doi.org/10.1177/1525740117716416

Dinnes, C., Hux, K., Holmen, M., Martens, A., \& Smith, M. (2018). Writing changes and perceptions after traumatic brain injury: "Oh, by the way, I can't write." Manuscript submitted for publication.

Englert, C. S., Raphael, T. E., Anderson, L. M., Anthony, H. M., Fear, K. L., \& Gregg, S. L. (1988). A case for writing intervention: Strategies for writing informational text. Learning Disabilities Focus, 3(2), 98-113.

Graham, S. (2018). A writer(s) within community model of writing. In C. Bazerman, V. Berninger, D. Brandt, S. Graham, J. Langer, S. Murphy, P. Matsuda, D. Rowe, \& M. Schleppegrell, (Eds.), The lifespan development of writing. Urbana, IL: National Council of English.

Graham, S., \& Perin, D. (2007a). A meta-analysis of writing instruction for adolescent students. Journal of Educational Psychology, 99, 445-476. doi: 10.1037/00220663.99.3.445

Graham, S., \& Perin, D. (2007b). Writing next: Effective strategies to improve writing 
of adolescents in middle and high schools. New York, New York: Carnegie Corporation.

Graham, S., Bollinger, A., Booth Olson, C., D’Aoust, C., MacArthur, C., McCutchen, D., \& Olinghouse, N. (2012). Teaching elementary school students to be effective writers: A practice guide (NCEE 2012- 4058). Washington, DC: National Center for Education Evaluation and Regional Assistance, Institute of Education Sciences, U.S. Department of Education. Retrieved from: https://ies.ed.gov/ncee/wwc/Docs/PracticeGuide/writing_pg_062612.pdf

Graham, S., Bruch, J., Fitzgerald, J., Friedrich, L., Furgeson, J., Greene, K., Kim, J., Lyskawa, J., Olson, C.B., \& Smither Wulsin, C. (2016). Teaching secondary students to write effectively (NCEE 2017-4002). Washington, DC: National Center for Education Evaluation and Regional Assistance (NCEE), Institute of Education Sciences, U.S. Department of Education. Retrieved from the NCEE website: https://ies.ed.gov/ncee/wwc/Docs/PracticeGuide/wwc_secondary_writing_110116. pdf

Graham, S., Harris, K. R., \& Chambers, A. B. (2016). Evidence-based practice and writing instruction: A review of reviews. In C. MacArthur, S. Graham, \& J. Fitzgerald (Eds.), Handbook of writing research, $2^{\text {nd }}$ edition (pp. 211-226). New York: Guilford Press.

Graham, S., Harris, K. R., \& Santangelo, T. (2015). Research-based writing practices and the common core: Meta-analysis and meta-synthesis. The Elementary School Journal, 115(4), 498-522. 
Harris, K. R., Graham, S., \& Mason, L. H. (2003). Self-regulated strategy development in the classroom: Part of a balanced approach to writing instruction for students with disabilities. Focus on Exceptional Children, 35(7), 1.

Hayes, J. R., \& Flower, L. S. (1980). Identifying the organization of writing processes. In L. W. Gregg \& E. R. Steinberg (Eds.), Cognitive processes in writing (pp. 3-30). Hillsdale NJ: Erlbaum \& Associates.

Kellogg, R. T. (1996). A model of working memory in writing. In C. M. Levy \& S. Ransdell (Eds.), The science of writing: Theories, methods, individual differences, and applications (pp. 57-71). Mahwah, NJ: Erlbaum.

Ledbetter, A. K., Sohlberg, M. M., Fickas, S. F., Horney, M. A., \& McIntosh, K. (2017). Evaluation of a computer-based prompting intervention to improve essay writing in undergraduates with cognitive impairment after acquired brain injury. Neuropsychological Rehabilitation, 1-30.

Mason, L. H., \& Graham, S. (2008). Writing instruction for adolescents with learning disabilities: Programs of intervention research. Learning Disabilities Research \& Practice, 23, 103-112.

National Commission on Writing (April, 2003). The neglected " $R$ ": The need for a writing revolution. New York: College Board. Retrieved from http://www.collegeboard.com/prod_downloads/writingcom/neglectedr.pdf

National Commission on Writing (May, 2006). Writing and school reform. New York: College Board. Retrieved from 
http://www.collegeboard.com/prod_downloads/writingcom/writing-school-reformnatl-comm-writing.pdf

Scardamalia, M., \& Bereiter, C. (1987). Knowledge telling and knowledge transforming in written composition. In S. Rosenberg (Ed.), Advances in applied psycholinguistics: Reading, writing, and language learning (vol. 2, pp. 142-175). New York: Cambridge University Press.

Singer, B. D. \& Bashir, A. S. (2004). EmPOWER: A strategy for teaching students with language learning disabilities how to write expository text. In E. R. Silliman \& L. Wilkinson (Eds.), Language and literacy learning (pp. 239-272). New York: Guilford.

Zimmerman, B., \& Reisemberg, R. (1997). Becoming a self-regulated writer: A social cognitive perspective. Contemporary Educational Psychology, 22, 73-101. 
Table 1. Comparison of EmPOWER's Components to Graham's (2018) Cognitive Model

Components of Graham's (2018) cognitive model EmPOWER

Control mechanisms

Attention

Working memory

Executive control

Long-term memory resources

Knowledge

I

Beliefs

Production processes

Conceptualization

Ideation

Translation

Transcription

Reconceptualization

Modulators

Emotions

Physical state

Personality traits

Note. $V=$ component is fully addressed by EmPOWER; / = aspects of the component is addressed by EmPOWER- = component is addressed by EmPOWER. 